\title{
STRUCTURE OF COORDINATION MOTOR ABILITIES IN MALE BASKETBALL PLAYERS AT DIFFERENT LEVELS OF COMPETITION
}

\author{
SADOWSKI JERZY ${ }^{1}$, WOŁOSZ PAWEŁ ${ }^{2}$, ZIELIŃSKI JANUSZ², NIŹNIKOWSKI TOMASZ, \\ BUSZTA MARIUSZ ${ }^{4}$
Józef Piłsudski University of Physical Education in Warsaw, Faculty of Physical Education and Sport in Biała Podlaska, Department of Athletics ${ }^{1}$, Department of Basketball and Handball', Department of Gymnastics ${ }^{3}$, Department of Foreign Languages ${ }^{4}$

\author{
Mailing address: Jerzy Sadowski, Faculty of Physical Education and Sport, Department of Athletics, \\ 2 Akademicka Street, 21-500 Biała Podlaska, tel.: +48 83 3428803, fax: +48 83 3428800, \\ e-mail: jerzy.sadowski@awf-bp.edu.pl
}

\begin{abstract}
Introduction. The purpose of this investigation was to examine the structure of coordination motor abilities (CMA) in male basketball players at different levels of competition. Material and methods. The study included 183 male basketball players from 10 Polish sports clubs. The examined groups consisted of seniors $(n=42)$ aged $24.5( \pm 3.3)$, juniors $(n=37)$ aged $16.8( \pm 0.6)$, cadets $(n=54)$ aged $14.5( \pm 0.1)$ and children $(n=50)$ aged $13.4( \pm 0.2)$. A battery of motor tests was administered to assess the following CMA: kinesthetic differentiation of movements, spatio-temporal orientation, reaction time, movement coupling, sense of balance, sense of rhythm and adjustment of movements. The structure of CMA under investigation was determined based on the results of Hotelling's principal component analysis in Ticker's modification, completed with Kaiser's Varimax rotation [1, 2]. Results. The CMA structure of basketball players was composed of three or four factors. Most often these included rhythm, movement differentiation, movement coupling and adjustment of movements. Less frequently the structure consisted of spatio-temporal orientation, balance and reaction time. An in-depth analysis of the CMA structure revealed that factors ranged from heterogeneous (children and cadets) to homogeneous ones (juniors and seniors). The distribution of identified factors in the common variance was the smallest in children and cadets (58.9\% and 62.9\%, respectively) and the biggest in juniors and seniors (69.3\% and 68.48\%, respectively).
\end{abstract}

Key words: team games, kinesthetic differentiation, rhythm, balance, reaction time

\section{Introduction}

In recent years an interest of researchers and sports practitioners in studies on coordination motor abilities has increased. It is believed that the quality of movement control and regulation is conditioned by coordination potential. This potential determines the possibility of performing effective motor actions [3].

The coordination potential is a group of coordination motor abilities (CMA) that Ljach [4] defines as "psychomotor capacities determining the readiness to control and regulate motor actions in an optimal manner".

Despite common recognition of the CMA importance in sport, the knowledge of their underlying mechanisms is insufficient. One reason is that studies on CMA have usually been conducted based on performance in selected motor tests. It made it more difficult to obtain reliable data on mechanisms underlying motor coordination. However, it ought to be emphasised that in recent years a number of researchers have incorporated more precise and accurate computer-based tools in CMA investigations, which may help us extend our knowledge about the human coordination potential and its conditioning [5, 6, 7, 8]. In spite of some limitations (mainly of methodological nature), CMA examinations based on motor tests provide a lot of interesting guidelines for practical applications in training [9] or physical education [10].

In recent years more and more research has been carried out regarding the influence of perceptual (mainly visual) training on effectiveness enhancement also in basketball players [11, 12]. It is assumed that an improvement in the functioning of receptors contributes to a better regulation of a movement whose integral part is motor coordination [8]. To date, however, research findings concerning the influence of perceptual training on the effectiveness of performing various motor tasks have been ambiguous $[13,14,15,16]$.

One of the aspects of examining coordination motor potential in sport were attempts at defining dominant CMA in team games [17]. The most important CMA included adjustment of movements, kinesthetic differentiation, spatio-temporal orientation, reaction time, rhythm, movement coupling, balance and free muscle relaxation [9]. Many researchers have investigated the structure of CMA in children and youth practising team sports $[18,19,20]$. Their findings confirmed that the CMA structure depends on age, gender, sport and sports level.

So far, studies on basketball players have also focused on latent structure of variables of sports preparation [21], defining correlations between CMA and the level of technical preparation $[22,23]$, determining relations between coordination and condition-related motor abilities [24, 25, 26], differences in motor abilities of European top-quality young female basketball players [27] and on selecting effective means and methods of coordination training [28, 29, 30, 31].

Some research concerned the role of CMA in the structure of special fitness in physical education students who were basketball players and those who did not do this sport [32]. The author proved that kinesthetic differentiation and spatio-tempo- 
ral orientation accounted for $34 \%$ of total variance. In turn, having investigated the structure of physical fitness in 13-year-old male basketball players, Karpowicz [33] revealed that the level of physical fitness index was determined to the largest extent by agility, speed and jumping abilities. Dembiński [23] observed that in male basketball players aged 11-12 oriented motor abilities including CMA accounted for $23 \%$ of game effectiveness.

Such a wide variety of research is the reason why a lot of issues remain unresolved and findings are ambiguous. It is the result of different methods, including observation, questionnaire, interview and motor tests, being applied to assess predominant CMA. This, in turn, stems from the fact that it is difficult to select proper homogeneous tests evaluating chosen CMA depending upon the specificity of a given sport. Moreover, a lot of studies were conducted only during one selected training mesocycle usually on low- and medium-level athletes, which considerably reduced the value of their findings. It is due to the aforementioned constraints that plenty of issues regarding the coordination potential and its role in sport remain unaccounted for.

Although a lot of researchers have identified the predominant CMA in basketball, to the best of our knowledge no investigations concerning the CMA structure in male basketball players at different levels of competition have been carried out with the use of the same tests. Getting to know this structure will make it possible to extend the knowledge about selecting adequate means and methods of coordination training and to plan it in the process of long-term training.

The aim of this study was to examine the structure of coordination motor abilities (CMA) in male basketball players at different levels of competition.

\section{Material and methods}

The study included 183 male basketball players from 10 Polish sports clubs. The subjects consisted of seniors $(n=42)$ aged $24.5( \pm 3.3)$, juniors $(n=37)$ aged $16.8( \pm 0.6)$, cadets $(n=54)$ aged $14.5( \pm 0.1)$ and children $(n=50)$ aged $13.4( \pm 0.2)$.

Selected data regarding the groups of subjects are presented in table 1.

Table 1. Characteristics of male basketball players under examination

\begin{tabular}{|l|c|c|c|c|}
\hline $\begin{array}{c}\text { Baskethall } \\
\text { players }\end{array}$ & \multirow{n}{n}{} & Age (years) & Body height $(\mathrm{cm})$ & Body mass $(\mathrm{kg})$ \\
\cline { 3 - 5 } & & $\bar{x}$ & $\bar{x}$ & $\bar{X}$ \\
\hline Seniors & 42 & $24.5( \pm 3.3)$ & $196.2( \pm 2.2)$ & $96.6( \pm 1.1)$ \\
\hline Juniors & 37 & $16.8( \pm 0.6)$ & $184.7( \pm 0.5)$ & $73.4( \pm 3.0)$ \\
\hline Cadets & 54 & $14.5( \pm 0.1)$ & $179.0( \pm 2.3)$ & $65.3( \pm 3.1)$ \\
\hline Children & 50 & $13.4( \pm 0.2)$ & $171.8( \pm 1.3)$ & $58.0( \pm 1.0)$ \\
\hline
\end{tabular}

A battery of motor tests was administered to assess the following CMA: kinesthetic differentiation of movements, spatiotemporal orientation, reaction time, movement coupling, sense of balance, sense of rhythm and adjustment of movements. One of the key methodological issues in examining the CMA structure in male basketball players at different levels of competition is to select tests that will not be too difficult for less advanced players and too easy for more skilled ones. Therefore, the tests employed in this investigation are frequently used and thoroughly described in literature. Their applicability has been confirmed many times [22, 34, 35]. Reliability of the tests was checked by means of the 'test-retest' method. Reliability coefficients ranged from 0.73 to 0.96 .

Kinesthetic differentiation was assessed with the test of free throws with different balls, i.e. balls of different sizes and mass [35]. Subjects performed 10 free throws with ball no. 5 (500 g) and ball no. 7 (650 g) alternately. A point scale was employed: 3 points for a successful free throw where the ball did not touch the rim and the backboard, 2 points for a successful throw where the ball touched either the rim or the backboard, 1 point for a missed throw with the ball touching either the rim or the backboard and 0 points for a completely missed throw (socalled air ball). The result was the total number of points scored in two sets.

Spatio-temporal orientation was evaluated by means of the run to numbered balls [34]. One $4 \mathrm{~kg}$ and five $3 \mathrm{~kg}$ medicine balls were used in this test. Standing beside ball no. 0 ( $4 \mathrm{~kg}$ ) and facing the supervisor, the subject had five numbered balls (from 1 to 5 ) arranged behind his back. The balls were placed 3 metres from ball no. 0 and $1.5 \mathrm{~m}$ from one another. The supervisor showed the number, whereupon the subject turned around, ran towards the ball, touched it and returned to ball no. 0 . When the subject touched ball no. 0, the supervisor showed another number. Time was recorded between the moment the subject touched ball no. 0 and the moment he finished performing the run for the third time. The test was repeated after a 10-minnutelong rest; however, this time it was the subject who decided which three balls to approach. The time difference between these two exercises was used in the analysis.

Time of reaction was measured with the help of the test of catching a rolling ball [34]. Two gymnastic benches were used in this test. One end of each bench was attached to a wall bar at the height of $120 \mathrm{~cm}$. The whole upper structure of the bench formed a strip $15 \mathrm{~cm}$ wide which was used for rolling the ball down. At a signal the supervisor let go of the ball from the upper edge of the bench, while the subject, who was standing backwards, turned around and caught the ball at the highest possible point of the bench. The test was carried out three times. An average distance that the ball covered was taken into account.

Movement coupling was assessed based on the test of rolling three basketballs [35]. At a distance of $10 \mathrm{~m}$ (with clearly marked lines of start and finish) three poles were set. The first one was situated $2.5 \mathrm{~m}$ from the starting line, while the other ones were positioned $2.5 \mathrm{~m}$ from each other. At a signal the subject performed a slalom run. Then, having rested for 5 minutes, he repeated the test. However, this time he had to roll three basketballs. The time difference between these two exercises was used in the analysis.

Body balance was evaluated by means of the test of turns on a gymnastic bench [34]. Standing on the $10 \mathrm{~cm}$ balance strip of an inverted bench, the subject performed eight 360 degree alternate turns in the shortest possible time. The test was repeated if the subject touched the ground more than four times. The time of proper performance was measured with an accuracy of $0.1 \mathrm{~s}$.

To assess rhythm, the hoop run test with and without bouncing was employed [34, 35]. At a distance of $28 \mathrm{~m}$ (with clearly marked lines of start and finish) gymnastic hoops were set. Three hoops were placed one after another $5 \mathrm{~m}$ away from the starting line, five loops were positioned $14 \mathrm{~m}$ from the starting line and three loops were put $5 \mathrm{~m}$ before the finishing line. At a signal the subject ran the whole distance placing one foot in each loop. After that he repeated the test twice - first bouncing the ball with the dominant hand and then with the non-dominant hand. The time difference between the test without the ball and the test with bouncing the ball with the dominant and the non-dominant hand was applied in the analysis.

Adjustment of movements was evaluated using the test of the dominant and the non-dominant hand dribbling around poles [35]. At a distance of $10 \mathrm{~m}$ (with clearly marked lines of start and finish) three poles were set. The first one was placed $2.5 \mathrm{~m}$ from the starting line, while the other ones were positioned $2.5 \mathrm{~m}$ from each other. The subject performed the test four times. First he ran with the poles on his right side and then 
on his left side. After that he dribbled around the poles using his dominant hand, whereupon he repeated the test dribbling with his non-dominant hand. There was a 5-minute interval between each attempt. The time difference between the test performance with and without the ball was taken into consideration.

In order to minimise the effects of the energetic factor on the assessment of such CMA as spatio-temporal orientation, movement coupling, sense of rhythm and adjustment of movements, the analysis included the time difference between test performances with and without the ball. It was assumed that it would minimise the 'suppression' of the informative component with energetic factors, which often occurs while assessing CMA with motor tests.

The structure of CMA under examination was determined with the use of the factor analysis. The variant employed in the study was based on Hotelling's principal component analysis in Tucker's modification, completed with Kaiser's Varimax rotation $[1,2]$.

\section{Results}

Depending on the task performed during a training session, CMA occur in various interrelations. The number of possible variants is so high that it is difficult to estimate it. Factor analysis results revealed that, depending on their sports level, 3 or 4 factors were distinguished in the structure of basketball players.

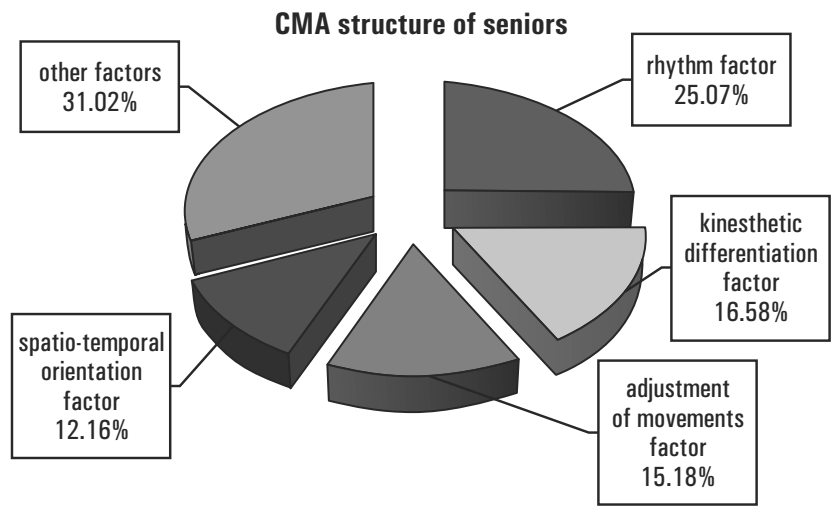

Figure 1. The structure of coordination motor abilities in seniors

In seniors four homogeneous factors were revealed. They accounted for $68.98 \%$ of common variance (fig. 1 ). The rhythm factor included the time difference of the hoop run test without dribbling and with dribbling using the dominant hand $\left(\mathrm{r}_{\mathrm{tk}}=0.89\right)$ and the non-dominant hand $\left(\mathrm{r}_{\mathrm{tk}}=0.80\right)$. This factor accounted for $25.07 \%$ of common variance. The second factor kinesthetic differentiation-included the test of free throws with different balls $\left(\mathrm{r}_{\mathrm{tk}}=0.75\right)$. It accounted for $16.58 \%$ of common variance. Adjustment of movements factor included the time difference between right- and left-hand side running around poles and dribbling around poles using the dominant hand $\left(\mathrm{r}_{\mathrm{tk}}=0.83\right)$ and the non-dominant hand $\left(\mathrm{r}_{\mathrm{tk}}=0.77\right)$. It accounted for $15.18 \%$ of common variance. The fourth factor - spatiotemporal orientation - was formed by the time difference of the run to numbered balls with and without showing numbers $\left(r_{t k}=0.94\right)$. It accounted for $12.16 \%$ of common variance.

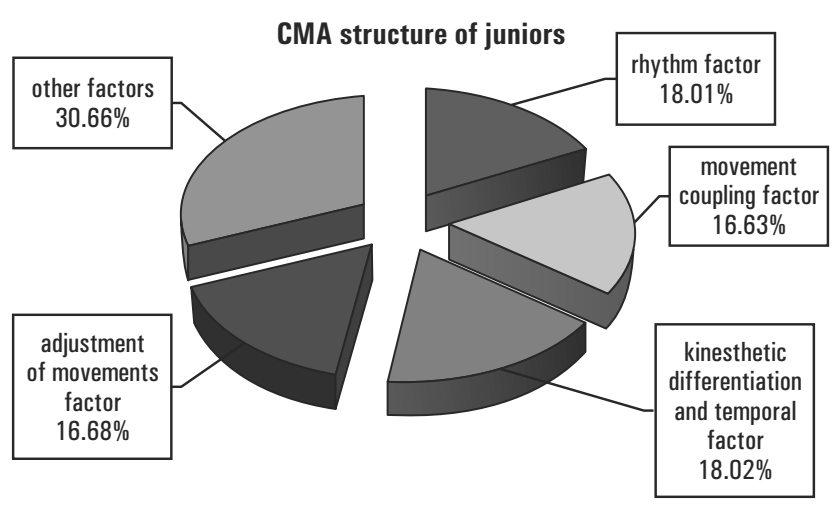

Figure 2. The structure of coordination motor abilities in juniors

The CMA structure of juniors was not as homogeneous as in seniors (fig. 2). Four factors were identified. They accounted for $69.34 \%$ of common variance. The rhythm factor included the time difference of the hoop run test without dribbling and with dribbling using the dominant hand $\left(\mathrm{r}_{\mathrm{tk}}=0.82\right)$ and the non-dominant hand $\left(\mathrm{r}_{\mathrm{tk}}=0.79\right)$. This factor accounted for $18.01 \%$ of common variance. Another factor - movement coupling - included the time difference of the test of running without basketballs and running with rolling basketballs $\left(\mathrm{r}_{\mathrm{tk}}=0.94\right)$. It accounted for $16.63 \%$ of common variance. The next factor covered the test of free throws with different balls $\left(r_{t k}=0.71\right)$ and the time difference of the run to numbered balls with and without showing numbers $\left(\mathrm{r}_{\mathrm{tk}}=0.76\right)$. It was defined as the factor of kinesthetic differentiation and spatio-temporal orientation. It accounted for $18.02 \%$ of common variance. The last factor of adjustment of movements included the time difference between left-hand side running around poles and dribbling around poles using the dominant hand $\left(\mathrm{r}_{\mathrm{tk}}=0.83\right)$ and the non-dominant hand $\left(\mathrm{r}_{\mathrm{tk}}=0.77\right)$. It accounted for $16.68 \%$ of common variance.

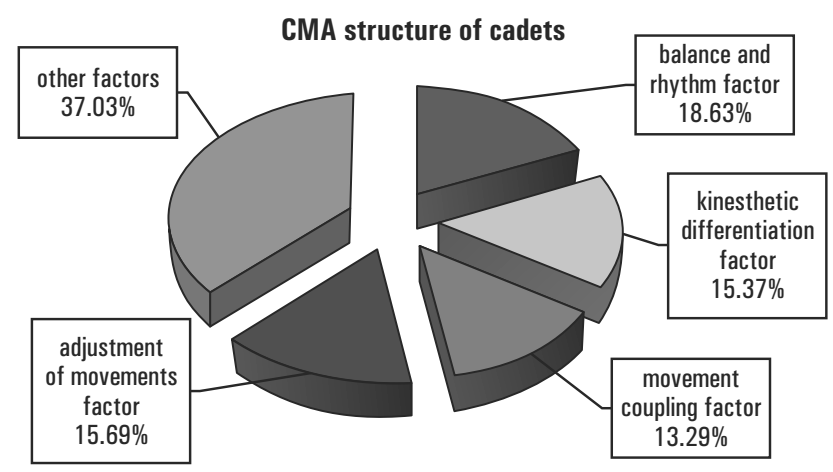

Figure 3. The structure of coordination motor abilities in cadets

As far as the CMA structure of cadets is concerned, four factors were found as well. They accounted for $62.97 \%$ of common variance (fig. 3). The factor of balance and rhythm included the test of turns on a gymnastic bench $\left(\mathrm{r}_{\mathrm{tk}}=0.78\right)$ and the time difference of the hoop run without bouncing and with bouncing using the non-dominant hand $\left(\mathrm{r}_{\mathrm{t} k}=0.82\right)$. It accounted for $18.63 \%$ of common variance. Kinesthetic differentiation factor consisted of the test of free throws with different balls. Although $\left(r_{k}=0.69\right)$, it was close to the value of 0.7 , which defines factors of the highest reliability. This factor accounted for $15.37 \%$ of common variance. The third factor - movement coupling - was formed by the time difference of the test of running without basketballs 
and running with rolling basketballs $\left(\mathrm{r}_{\mathrm{t} k}=0.77\right)$. It accounted for $13.29 \%$ of common variance. The fourth factor - adjustment of movements - included the time difference between left-hand side running around poles and dribbling around poles using the dominant hand $\left(r_{t k}=0.78\right)$. It accounted for $15.69 \%$ of common variance.

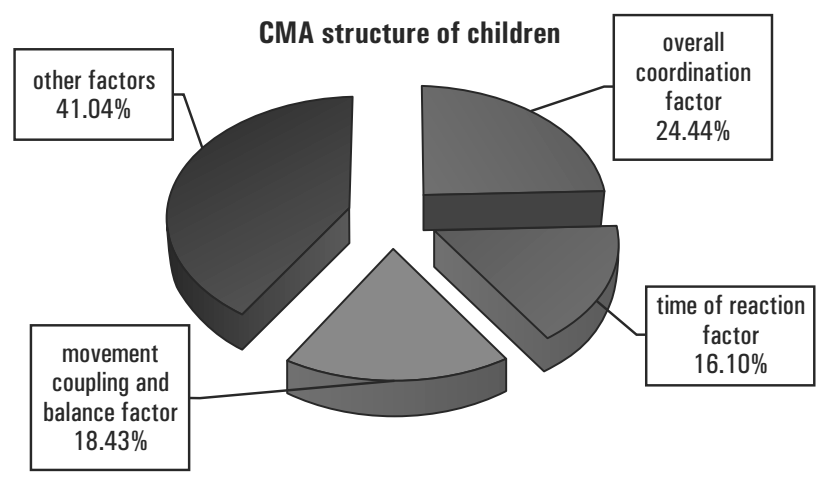

Figure 4. The structure of coordination motor abilities in children

Only three independent factors were observed in the CMA structure of children. In total, they accounted for $58.96 \%$ of common variance (fig. 4). The first factor was named the factor of overall coordination, as it was composed of three tests assessing kinesthetic differentiation, rhythm and adjustment of movements: free throws with different balls $\left(\mathrm{r}_{\mathrm{t} k}=0.71\right)$, the time difference of the hoop run without bouncing and with bouncing using the dominant hand $\left(\mathrm{r}_{\mathrm{tk}}=0.79\right)$ and the time difference between left-hand side running around poles and dribbling around poles using the dominant hand $\left(\mathrm{r}_{\mathrm{t} k}=0.79\right)$. This factor accounted for $24.44 \%$ of common variance. The next factor - time of reactionwas not found in the other groups. It accounted for $16.10 \%$ of common variance and it included the test of catching a rolling ball $\left(r_{t k}=0.70\right)$. The factor of movement coupling and balance consisted of the test assessing movement coupling - the time difference of the test of running without basketballs and running with rolling basketballs $\left(\mathrm{r}_{\mathrm{tk}}=0.75\right)$, and the test evaluating dynamic balance - turns on a gymnastic bench $\left(\mathrm{r}_{\mathrm{tk}}=0.72\right)$. They accounted for $18.43 \%$ of common variance. The findings concerning the CMA structure of children indicate that these factors were not homogeneous.

\section{Discussion}

Coordination motor abilities play an important role in basketball training. Not only are they crucial in the process of acquiring and improving basic technical skills but also they determine the efficiency of a player and his activities during a game. The CMA development requires systematic, wellplanned and logical selection of training means with regard to gender and sports level. The training means must be chosen neither in an intuitive way nor without considering any research findings. Only by implementing a meticulously planned training procedure that affects proper CMA in a given period will it be possible to produce the desired outcome.

All that is hard to achieve without learning the structure of CMA. Therefore, this study sought to analyse and learn the CMA structure in male basketball players at different levels of competition. The same methods were employed, as they enabled us to recognise and compare the CMA structure in male basketball players at various stages of training. It was revealed that the CMA structure in basketball players consisted of three or four factors. These usually included rhythm, differentiation of movements, movement coupling and adjustment of movements. Sometimes they included spatio-temporal orientation, balance and reaction. The obtained CMA structure is partially in line with the findings of many researchers who attempted to define the dominant CMA in basketball players. They usually listed reaction time, differentiation of movements, movement coupling and adjustment of movements [9, 36]. In turn, Raczek [37] considers spatio-temporal orientation, reaction time and kinesthetic differentiation of movements to be the most significant in basketball.

Ljach [9, 28] proved that the predominant CMA in all team sports were as follows: adjustment of movements, spatio-temporal orientation, reaction time and kinesthetic differentiation.

The analysis of the aforementioned findings shows that the opinions of even the same authors tend to change slightly in the course of further research. It may stem from the fact that many authors made use of different (mainly motor) tests while assessing CMA in basketball players at different levels of competition. In their opinion, CMA which correlated with various technical skills most often ought to be treated as predominant. This may well be the reason why some discrepancies were found. In their tests the energetic factor may have led to the 'suppression' of the informative component. As a consequence, this factor may have hindered the manifestation of coordination aspects. It does not mean that such findings are not interesting. However, it is difficult to compare them when it comes to groups at different levels of competition.

As highlighted by Raczek [8], getting to know the whole structure of coordination motor abilities requires diverse approaches, strategies and research methods. Therefore, in our study the same tests were employed at all levels, which enabled us to analyse the CMA structure using comparable indices. In order to minimise the 'suppression' of the coordination aspect with energetic factors, the analysis included the time difference between parts of test performances with and without the ball as well as with and without showing numbers. An in-depth analysis of the CMA structure revealed that factors ranged from heterogeneous (children and cadets) to homogeneous ones (juniors and seniors). In the group of children, one factor consisted of as many as three tests characterising various CMA; both in cadets and juniors there were two tests, whereas in the group of seniors only homogeneous factors were observed. Our findings are indirectly parallel to those of Kubaszczyk [22]. He found that the influence of CMA on technical skills depended on sports levels of subjects. He also stated that the number of statistically significant relations between CMA and technical skills decreased considerably together with an increase in age and training experience of basketball players. It may prove that at higher levels there occur some peculiar and often individual characteristics. As a result, the number of CMA drops, which affects the levels of technical skills. Simultaneously, dominant CMA typical of a given sport become more important. It shows that it is indispensable to select proper means in CMA training and to adopt an individual approach to training depending on sports levels.

The distribution of identified factors in the common variance was the smallest in children and cadets (58.9\% and $62.9 \%$, respectively) and the biggest in juniors and seniors (69.3\% and $68.48 \%$, respectively).

Our findings shed new light on the place and importance of rhythm in the training of male basketball players at different levels of competition. To date, rarely have researchers pointed to the sense of rhythm as one of the leading CMA in basketball $[7,20,38]$. It ought to emphasised that rhythm is strongly determined genetically and its levels in basketball players under investigation were high. That is probably why it is discernible in the CMA structure. The occurrence of this ability in the CMA 
structure at all levels may prove that the specific character of basketball is a proper stimulus conducive to the development of rhythm. This view is borne out by research carried out on a large number of subjects [20]. They treat rhythm as one of the most crucial CMA in team sports, among 11-14-year-old male basketball players in particular. Rhythm was noticeable already in children. However, spatio-temporal orientation and reaction as heterogeneous factors were observed only in juniors and as homogeneous factors only in seniors. It is common knowledge that spatial orientation depends on sensitivity of visual, auditory and tactile receptors as well as kinesthetic sensibility and balance. Long-term basketball training is likely to have increased sensitivity of visual receptors and, consequently, developed spatial orientation, which caused this factor to be distinguished in the CMA structure. Nonetheless, these are only our suppositions since standpoints on perceptual training are different [14].

All in all, it may be stated that the research revealed an actual distribution of selected aspects of the CMA structure in male basketball players at different levels of competition. The dominant CMA were observed at every stage of training. Moreover, those CMA which are an indispensable part of the CMA structure at every stage of training were revealed. A limitation of the study is the fact that its findings refer mainly to practical applications in sports training and physical education, yet they do not explain the mechanisms underlying coordination.

\section{Literature}

1. Czyż T. (1971). The application of the factor analysis method in studying the economic and regional structure of Poland. Geographical Studies. Wrocław: PAN. [in Polish].

2. Weber E. (1982). Mathematical fundamentals of genetics. Verlag: Jena VEB Gustav Fischer. [in German]

3. Raczek J. (2010). Antropomotorics. Theory of human motorics. Warszawa: Medical publishing PZWL. [in Polish].

4. Ljach W. (1979). Factor structure of dexterity in the position of multi-level system of controlling movements. Teoria i Praktika Fizyczeskoj Kultury 5, 51-53. [in Russian]

5. Zając A., Mikołajec K., Kubaszczyk A. (1993). Development of coordination abilities in the process of fitness preparation of a basketball player. Scientific annual AWF in Katowice 21, 135-147. [in Polish].

6. Zwierko T., Lesiakowski P., Florkiewicz B. (2005). Selected aspects of motor coordination in young basketball players. Human Movement Science 6, 124-128.

7. Sadowski J., Jaślikowska-Sadowska T., Wołosz P., Zieliński J. (2003). Coordination motor abilities and technical skills of young basketball players. In W. Starosta, W. Osiński (eds), New ideas in sport sciences: current issues and perspectives (pp. 224-227). Leszno: PWSZ.

8. Raczek J., Juras G., Waśkiewicz Z. (2000). New methods of assessing coordination motor abilities. Professional Sport 34, 14-27. [in Polish].

9. Ljach W. (2007). Coordination motor abilities and their significance for technical and tactical skills, methodology of development. In A. Zając, Z. Waśkiewicz (eds), Science for professional sport (pp. 23-61). Katowice: AWF Katowice. [in Polish].

10. Gallotta M. C., Marchetti R., Baldari C., Guidetti L., Pesce C. (2009). Linking co-ordinative and fitness training in physical education settings. Scandinavian Journal of Medicine $\mathcal{F}$ Science in Sports 19, 412-418.

11. Miller S., Bartlett R. (1996). The relationship between basketball shooting kinematics, distance and playing position. Journal of Sports Sciences 14, 243-253.

12. Oudejans R., Koedijker J. (2010). Perceptual training for basketball shooting. In I. Renshaw, K. Davis (eds.), Motor Learn- ing in Practice (pp. 47-56). New York: Routladge.

13. Kioumourtzoglou E., Kourtessis T., Michalopoulou M., Derri V. (1998). Differences in several perceptual abilities between experts and novices in basketball, volleyball and waterpolo. Perceptual Motor Skill 86; 899-912.

14. Abernethy B., Wood J.M. (2001). Do generalized visual training programmes for sport really work? An experimental investigation. Journal Sport Science 19, 203-222.

15. Elmurr P. (2000). Assessing and Training Eye-Hand Coordination. Miejsce Wydania: Sports Vision Summer, 8-10.

16. Balasaheb T., Maman P., Sandu J.S. (2008). The impact of visual skills training on batting performance in cricketers. Serbian Journal of Sports Sciences 2(1),17-23.

17. Diaczuk J., Pawelak Z. (2001). Levels of specific coordination motor abilities (CMA) and selected technical elements in active and retired female handball players - differences and correlations. Man and Movement 3, 58-60. [in Polish].

18. Pawelak Z., Witkowski Z. (2004). The structure of coordination motor abilities in elite female handball players. In S. Żak, M. Spieszny, R. Rzepka (eds.), Science in theory and practice of handball (pp. 107-112). Kraków: AWF Kraków. [in Polish].

19. Mikołajec K., Rzepka R. (2007). Objective assessment and importance of stability and motor control in sports performance. Journal of Human Kinetics 18, 135-140.

20. Brodani J., Šimonek J. (2010). Strukture of coordination capacities and prediction of overall coordination performance in selected sports. Slovakia: Editura Universitatii din Oradea.

21. Jukič I., Milanovič D., Vuleta D. (2005). The latent structure of variables of sports preparation and athletic preparendess based on physical conditioning contents in basketball. Kinesjology 37(2), 182-194.

22. Kubaszczyk A. (2001). Level of coordinational motor abilities and technical skills of basketball players. Physical Education and Sport 4, 499-515.

23. Dembiński J. (1997). Activity effectiveness in a game as a criterion for the individualisation of training tasks as exemplified by basketball. Training 3, 123-134. [in Polish].

24. Brooks M.A., Boleach L.W., Mayhew J.L. (1987). Relationship of specific and non-specific variables to successful basketball performance among high school players. Perceptual and Motor Skills 64, 832-827.

25. Franciosi E., Guidetti L., Gallotta M., Emerenziani G., Baldari C. (2010). Contributions of selected fundamental factors to basketball performance in adult players with mental retardation. Journal of Strenght \& Conditioning Research 24(8), 2166-71.

26. Pavlidou S., Michalopoulou M., Aggeloussis N., Kioumourtzoglou E. (2006). Relationship between perceptual and motor abilities on fundamental basketball skills in 8-13 years old children. Sport \& Physical Education 4, 399-408.

27. Erčulj F., Blas M., Čoh M., Bračič M. (2009). Differences in motor abilities of various types of European young elite female basketball players. Kinesiology 41(2), 203-211.

28. Ljach W. (2001). Coordination training in team games: selected theoretical and methodical attitudes. Man and Movement 3, 46-49. [in Polish].

29. Nieber L., Glasauer G. (2000). Theoretical fundamentals of regular coordination training in basketball. Leistungssport 30(5), 28-37. [in German]

30. Zieliński J., Sadowski J. (2005). Dynamics of selected coordination abilities and their connection with game effectiveness in young basketball players in a yearly cycle. In A. Kuder, K. Perkowski, D. Śledziewski (eds), Directions of training improvement-diagnostics (pp. 155-158). Warszawa: AWF Warszawa. [in Polish].

31. Manolopoulos E., Papadopoulos C., Kellis E. (2006). Effects of combined strength and kick coordination training on soccer kick biomechanics in amateur players. Scandinavian Jour- 
nal of Medicine $\&$ Science in Sports 16, 102-110.

32. Zwierko T. (1998). Correlation between coordination motor abilities and special basketball fitness in physical education students. In D. Umiastowska (ed.), Aktywność ruchowa ludzi w różnym wieku (pp. 436-441). Szczecin: Polskie Towarzystwo Naukowe Kultury Fizycznej. [in Polish].

33. Karpowicz K. (2006). Interrelation of selected factors determining the effectiveness of training in young basketball players. Human Movement 2, 130-146.

34. Hirtz P. (1985). Coordination skills in school sport. Berlin: Volk und Wissen. [in German]

35. Ljach W. (1998). Tests in physical education of students. Moskva. [in Russian]
36. Brill M.S. (1980). Selection in team sports. Fizkultura i Sport, 26-29. [in Russian]

37. Raczek J. (1989). The role of coordination motor abilities in the process of learning sports skills in children and youth. Scientific Quarterly 50, 21-27. [in Polish].

38. Starosta W., Stronczyński W. (2010). Significance of rhythm in learning and improving movement technique. Warszawa: Association of Sport Kinetics. [in Polish]

Submitted: April 28, 2014

Accepted:December 4, 2014 